\title{
Ischemic colitis following colonoscopy in an elderly patient on cardiovascular medication
}

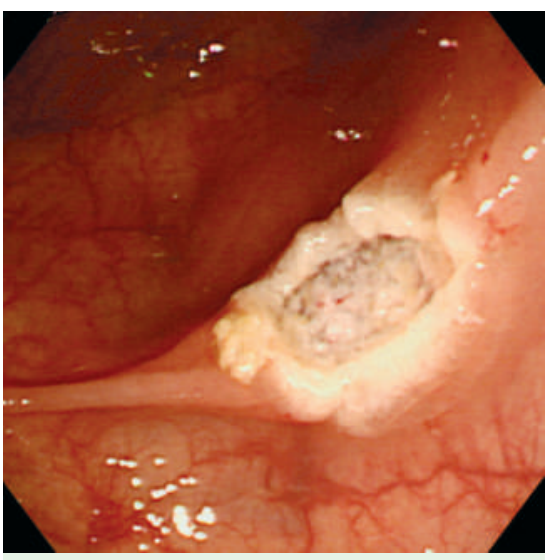

Fig. 1 The mucosa around a polypectomy site in the sigmoid colon showed no inflammation immediately after the procedure. No significant findings were noted except for three additional polyps in different locations.

Ischemic colitis is an uncommon complication following colonoscopy, with only four reports so far in the literature in English [1-4].

An 81-year-old woman underwent a total colonoscopy for assessment, prompted by occasional abdominal pain and a positive fecal occult blood test. For cleaning of the large bowel, she ingested a solution of magnesium citrate. Four colonic polyps were endoscopically resected, including one in the sigmoid colon that was $1.5 \mathrm{~cm}$ in size ( $\bullet$ Fig. 1).

She had been receiving nicardipine hydrochloride, propranolol hydrochloride, and digoxin for hypertension and infrequent palpitations over 40 years. She had no history of connective tissue disease.

The patient complained of abdominal pain in the left lower quadrant, 2 hours later, and this was followed by intermittent fresh bleeding from the anus overnight. On the next day, she had an elevated white blood cell (WBC) count (10 100/ $\mu \mathrm{L})$, reduced hemoglobin level $(12.4 \mathrm{~g} / \mathrm{dL})$, and raised C-reactive protein (CRP) level (3.82 $\mathrm{mg} / \mathrm{dL})$, compared with the values before polypectomy $(6200 / \mu \mathrm{L}, 13.9 \mathrm{~g} / \mathrm{dL}$, and $0.09 \mathrm{mg} / \mathrm{dl}$, respectively). An emergency colonoscopy was then performed, which disclosed a segmental area of long-
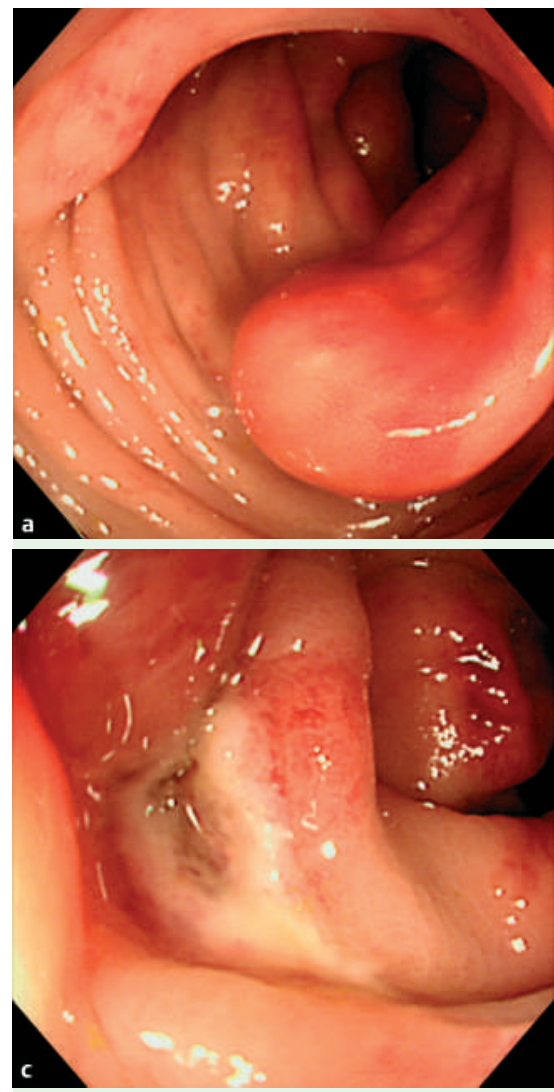

Fig. 2 Findings of the colonoscopy performed on the next day. a An ischemic segment started abruptly around the middle of the sigmoid colon. Hyperemic and edematous changes in the mucosa as well as loss of vascularity were prominent, whereas the pit pattern of the affected mucosa remained within normal structural range. b Fine granular petechiae formed two

itudinal petechial hemorrhages with edematous mucosa between the middle sigmoid colon and the sigmoid-descending colon junction ( $\bullet$ Fig. 2 ), that was compatible with findings of ischemic colitis. The possibility of bleeding from any of the polypectomy sites was excluded by the complete colonoscopy examination ( $\bullet$ Fig. 2c). The patient made an uneventful recovery with conservative treatment, and her WBC count and CRP returned to normal levels in one week. She was discharged 8 days after the first colonoscopy.

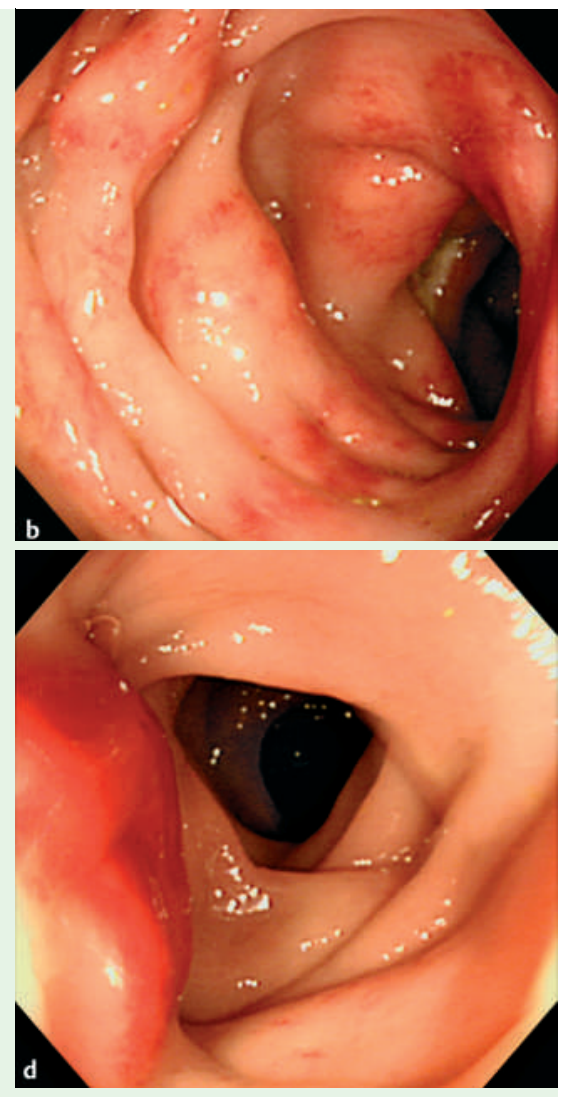

longitudinal streaks. $\mathrm{c}$ One polypectomy site identical to that in Fig. 1 was involved in the ischemic segment, but no bleeding was observed from the post-polypectomy ulcer. $\mathbf{d}$ The affected mucosa ended near the sigmoid-descending colon junction, and the oral lumen appeared normal up to the cecum.

According to a recent review, colonoscopy itself can be a causative procedure that predisposes to colonic ischemia [5]. In addition, antihypertensive agents and digoxin may decrease intestinal blood flow and have been postulated as risk factors [5]. We speculate that intake of these drugs also contributed to the disease manifestation in this patient.

Endoscopy_UCTN_Code_CPL_1AJ_2AB 
H. Nozawa ${ }^{1,2}$, Y. Akiyama ${ }^{1,3}$, S. Sunaga ${ }^{4}$, G. Tsurita ${ }^{2}$

1 Department of Surgery, Odaira Memorial Tokyo Hitachi Hospital, Japan

2 Department of Surgical Oncology, University of Tokyo Hospital, Japan

3 Head Office Health Care Center, Head Office Clinic, Hitachi Ltd, Tokyo, Japan

4 Department of Internal Medicine, Odaira Memorial Tokyo Hitachi Hospital, Japan

\section{References}

1 Wheeldon NM, Grundman MJ. Ischaemic colitis as a complication of colonoscopy. BM] 1990; 301: 1080-1081

2 Church JM. Ischemic colitis: complicating flexible endoscopy in a patient with connective tissue disease. Gastrointest Endosc 1995; 41: 181 - 182

3 Cremers MI, Oliveira AP, Freitas J. Ischemic colitis as a complication of colonoscopy. Endoscopy 1998; 30: S54

4 Versaci A, Macri A, Scuderi $G$ et al. Ischemic colitis following colonoscopy in a systemic lupus erythematosus patient: report of a case. Dis Colon Rectum 2005; 48: 866-869

5 Green BT, Tendler DA. Ischemic colitis: a clinical review. South Med J 2005; 98 : $217-222$
Bibliography

DOI $10.1055 / \mathrm{s}-2007-995329$

Endoscopy 2007; 39: E344-E345

(c) Georg Thieme Verlag KG Stuttgart · New York . ISSN 0013-726X

Corresponding author

\section{H. Nozawa, MD PhD}

Department of Surgery

Odaira Memorial Tokyo Hitachi Hospital

3-5-7 Yushima, Bunkyo-ku

Tokyo 113-0034,

Japan

Fax: $+81-3-38375916$

hiroanozawa-gi@umin.ac.jp 